\title{
Erratum to: Design of a Lentiviral Vector for the Inducible Expression of MYC: A New Strategy for Construction Approach
}

\author{
Onur Tokgun $^{1} \cdot$ Francesco Paolo Fiorentino $^{2,3,4} \cdot$ Pervin Elvan Tokgun $^{1} \cdot$ Jun Yokota $^{2} \cdot$ Hakan Akca $^{1}$
}

Published online: 8 June 2017

(C) Springer Science+Business Media New York 2017

\section{Erratum to: Mol Biotechnol \\ DOI 10.1007/s12033-017-0006-y}

Unfortunately in the original publication, the affiliations associated with the author Francesco Paolo Fiorentino were incomplete. Also the order of affiliations should be changed. The corrected list of affiliations is given in this erratum.

The online version of the original article can be found under doi:10.1007/s12033-017-0006-y.

Hakan Akca

hakca@pau.edu.tr

1 Department of Medical Biology, Pamukkale University School of Medicine, Denizli, Turkey

2 Genomics and Epigenomics of Cancer Prediction Program, Institut d'Investigació Germans Trias i Pujol (IGTP),

Barcelona, Spain

3 Department of Biomedical Sciences, University of Sassari, Sassari, Italy

4 Kitos Biotech srls, Porto Conte Ricerche, 07041 Alghero, Italy 